\title{
THE ROLE OF TRIGLYCERIDE TO HDL CHOLESTEROL RATIO IN SERA AS A CLINICAL SURROGATE MARKER FOR CARDIOVASCULAR RISK AND INSULIN RESISTANCE IN PATIENTS WITH METABOLIC SYNDROME
}

\section{Silviya S. Ganeva, Ginka H. Rayanova, Katya N. Todorova, Tzvetan H. Lukanov', Svetla O. Blazheva ${ }^{1}$}

Clinic of Endocrinology and Metabolic Diseases,

Dr. Georgi Stranski University

Hospital - Pleven

${ }^{1}$ Medico-Diagnostic Laboratory of

Immunology,

Dr. Georgi Stranski University

Hospital - Pleven

\author{
Corresponding Author: \\ Silviya Ganeva \\ Dr. Georgi Stranski University Hospital - \\ Pleven, \\ Clinic of Endocrinology and Metabolic \\ Diseases \\ 91, Vladimir Vazov Str. \\ Pleven, 5800 \\ Bulgaria \\ e-mail: doctorganeva@gmail.com
}

Received: January 28, 2021

Revision received: May 20, 2021

Accepted: July 08, 2021

\section{Summary}

The study aimed to investigate the triglycerides to HDLcholesterol ratio $(\mathrm{Tg} / \mathrm{HDL})$ and the interaction of this ratio with insulin resistance (IR) and insulin secretion indices, with the levels of interleukin - 1(IL-1), interleukin-6 (Il6 ), and tumour necrotic factor- $\alpha$ (TNF- $\alpha$ ) in sera among patients with metabolic syndrome (MS). A prospective, cross-sectional, comparative study was conducted on 45 patients with MS without data for hyperglycemia and 21 metabolically healthy non-obese controls. The levels of fasting and postprandial glucose, immunoreactive insulin (IRI), total cholesterol, triglycerides (Tg), IL-1, IL-6, and TNF- $\alpha$ were measured in all the participants. We calculated the LDL cholesterol levels, Tg/HDL ratio, homeostatic model of insulin resistance (HOMA-IR), and the homeostatic model of $\beta$-cell function (HOMA-b). Patients with MS had higher BMI ( $38.73 \pm 1.84$ vs. $24.32 \pm 2.71 \mathrm{~kg} / \mathrm{m} 2 ; \mathrm{p}<0.05)$ and waist circumference $(115.56 \pm 4.7$ vs. $81.1 \pm 8.4 \mathrm{~cm} ; \mathrm{p}<0.05)$ than non-obese controls. The same patients had higher LDL cholesterol levels $(3.42 \pm 0.3$ vs. $2.63 \pm 0.66 \mathrm{mmol} / \mathrm{l} ; \mathrm{p}<0.05)$ and $\mathrm{Tg}(1.59 \pm 0.22$ vs. $1.08 \pm 0.31 \mathrm{mmol} / 1 ; \mathrm{p}<0.05)$, as well as lower levels of HDL-cholesterol $(1.03 \pm 0.09$ vs. 1.27 $\pm 0.24 \mathrm{mmol} / 1 ; \mathrm{p}<0.05)$ compared to the controls. The Tg/ HDL ratio was $2.03 \pm 0.87$ among the patients with MS and $0.88 \pm 0.27$ in controls; $p<0.05$. The plasma levels of basal IRI $(19.32 \pm 3.22 \mathrm{mIU} / 1$ vs. $9.13 \pm 0.73 \mathrm{mIU} / \mathrm{l} ; \mathrm{p}<0.05)$, HOMAIR (4.02 vs. $1.97 ; \mathrm{p}<0.05)$ and HOMA-b $(258.77 \pm 57.76$ vs. $183.31 \pm 17.52 ; \mathrm{p}<0.05)$ were significantly higher in the MS group. The same patients with MS had higher concentrations of IL-1 $(18.37 \pm 4.28 \mathrm{pg} / \mathrm{ml}$ vs. $7.12 \pm 1.74 \mathrm{pg} / \mathrm{ml} ; \mathrm{p}<0.05)$, IL-6 $(1.01 \pm 0.3 \mathrm{pg} / \mathrm{ml}$ vs. $0.1 \pm 0.3 \mathrm{pg} / \mathrm{ml} ; \mathrm{p}<0.05)$ and TNF- $\alpha$ $(2.13 \pm 1.43 \mathrm{pg} / \mathrm{ml}$ vs. $1.82 \pm 0.94 \mathrm{pg} / \mathrm{ml} ; \mathrm{p}=0.24)$ too. Positive correlations between the levels of IL- 1 and $\mathrm{Tg} / \mathrm{HDL}$ ratio $(\mathrm{r}=0.46 ; \mathrm{p}=0.008), \mathrm{IL}-1$ and HOMA-\%B $(\mathrm{r}=0.47 ; \mathrm{p}=0.005)$ were found. The Tg/HDL ratio is a potential, cheap and available surrogate marker for screening for cardiovascular risk and insulin resistance in patients with MS in clinical practice.

Keywords: metabolic syndrome, insulin resistance, atherogenic index, cytokines.

\section{Introduction}

Metabolic syndrome (MS) is considered a combination of risk factors for developing cardiovascular diseases and diabetes mellitus type 2 (DMT2). Insulin resistance (IR) is at the core of the modern MS concept. All expert 
groups which developed the criteria for clinically defining MS $[1,2,3]$ regard visceral obesity as the main component. Its combination with arterial hypertension, dyslipidemia, and hyperglycemia accelerates the progression of atherosclerosis. Malfunctions in secretion and metabolic effects of adipocytokines [interleukin-1(IL-1), interleukin6(IL-6), tumor-necrotic factor- $\alpha(\mathrm{TNF}-\alpha)]$ were found to be associated with visceral obesity [4]. They systematically affect the central nervous system, cardiovascular system, pancreas, liver and affect vessel and tissue inflammation, coagulation, and fibrinolysis [5]. They also play a role in regulating carbohydrate metabolism, insulin sensitivity, and the showcase of IR [6,7].

Laboratory finds of atherogenic dyslipidemia in MS include hypertriglyceridemia, lowered serum levels of HDL-cholesterol and apolipoprotein A1-(ApoA-1), increased fractions of small dense LDL-cholesterol particles, and apolipoprotein B (ApoB) in plasma. Levels of small dense LDL-cholesterol fractions are considered the most substantial predictive factor for cardiovascular diseases [8]. However, direct measurement of those is technically challenging and is not a standard routine laboratory testing.

The TG/HDL cholesterol ratio is identified as a surrogate predictive marker for atherosclerosis. Calculating it as an atherogenic index is simple and easy.

Several direct and indirect methods for determining IR can be used in patients with MS and at high cardiovascular risk [9]. The hyperinsulinemic-euglycemic clamp technique is regarded as the gold standard. Unfortunately, this method is complicated and requires much time, so it is inappropriate for epidemiological studies and clinical practice. Because of this, indirect indices have been developed for determining IR as the homeostatic model for insulin resistance [Homeostasis Model Assessment (HOMA)- HOMA- IR] [10]. However, the lack of a standardized methodology for studying endogenous insulin is a limiting factor for using this model in clinical practice [11].

Some studies define the increased ratio of TG/HDL as a good indicator of liver IR [12,13] and as a predictor for the development of DMT2 [14]. Unfortunately, there is not much data available regarding the clinical administration of the TG/HDL ratio as an IR assessment index.
We aimed to investigate the triglycerides to HDL-cholesterol ratio ( $\mathrm{Tg} / \mathrm{HDL}$ ) and interaction of this ratio with insulin resistance and insulin secretion indices, with the levels of interleukin -1(IL-1), interleukin-6 (Il-6), and tumour necrotic factor- $\alpha$ (TNF- $\alpha)$ in sera in the patients with metabolic syndrome (MS).

\section{Methods and Patients}

A prospective, cross-sectional, comparative, case-control study was conducted on 45 patients (men and women) with MS. The participants in the study were selected from patients hospitalized at the Clinic of Endocrinology of Dr. Georgi Stranski University Hospital Pleven, after their signing informed consent forms for participation in the study. Their results, obtained from investigations, were compared to those of 21 healthy non-obese controls ( 9 men and 12 women). The diagnosis MS was accepted according to the one in the primary medical documentation with less than 3 out of 5 positive diagnostic criteria of IDF (International Diabetes Federation) from 2010. Data for smoking habits, arterial hypertension, family history for cardiovascular diseases, and diabetes was collected by interviewing the participants. Height and weight were measured, and BMI was calculated for each patient. Their waist measurements were taken using standard methods. Arterial blood pressure was measured according to the recommendations of Thomas [20]. The patients with systolic blood pressure $\geq 130 \mathrm{mmHg}$ or/and diastolic blood pressure $\geq$ $85 \mathrm{mmHg}$, or/and taking antihypertensive drugs were considered hypertensive.

Blood samples in a fasting state were collected in the morning by venipuncture. The lab tests were performed at the clinical laboratory of the University Hospital, whose activities are regulated by the National System for Laboratory Control. The plasma triglycerides, total cholesterol, and HDL-cholesterol levels were examined using an enzyme-colorimetric method (automatic analyzer BA 400; BioSystems S.A, Spain). The values of LDL cholesterol were calculated by Friedewald's formula. Carbohydrate metabolism was evaluated by oral glucose tolerating test (OGTT) with 75 grams of glucose. Blood glucose was measured in 
venous plasma at 0,60 , and 120 minutes of the OGTT by applying the glucose oxidase method (KABE Labortechnik, Denmark; Beckman Glucose Analyzer, USA). The insulin levels were also monitored at 0,60 , and 120 minutes by enzyme-linked immunosorbent assay ELISA (Stat Fax 2100; Awareness Technology, USA). Two indirect methods were used for insulinresistance assessment: 1) Homeostatic Model Assessment for Insulin Resistance (HOMA-IR); HOMA IR $=$ fasting insulin $(\mathrm{mIU} / \mathrm{l}) \times$ fasting plasma glucose $(\mathrm{mmol} / \mathrm{l}) / 22.5$, with reference range for HOMA-IR- from 0.7 to 2.4 [21]; 2) Tg/ HDL ratio $[\mathrm{Tg} / \mathrm{HDL}$ ratio $=$ plasma triglycerides $(\mathrm{mmol} / \mathrm{l}) /$ levels of HDL- cholesterol in plasma $(\mathrm{mmol} / \mathrm{l})]$.

The HOMA-b model for assessment of $\beta$-cells function was used. HOMA- $\%$ b was calculated using the following formula: $20 \mathrm{x}$ fasting serum insulin (mIU/l)/fasting plasma glucose (mmol/1)-3.5 [21]. Adipocytokines - Il1, IL-6, and TNF- $\alpha$ (Gen-Probe Diaclone SAS, France) were determined by ELISA (Stat Fax 2100; Awareness Technology, USA).

All statistical analyses were performed using STATGRAPHICS Centurion XV.I. Data are presented as their mean values and standard deviations (means $\pm \mathrm{SD}$ ) or individual data and median values. Comparisons between the groups were made using the independent sample t-test for parametric comparison of the two means, the Kolmogorov-Smirnov test for a nonparametric comparison, and the Mann-Whitney tests for the test median of two groups. Twosided $\mathrm{P}$ values $<0.05$ were considered to indicate statistically significant differences. The Pearson (r) correlation for measuring the strengths of association between two variables was also done.

\section{Results}

In the study group, $62.5 \%$ of the patients with MS had a family history of cardiovascular disease vs. $45.5 \%$ of the subjects from the control group. There was a positive family history for DMT2 in $53.13 \%$ of the MS group and $50 \%$ of the controls.

The clinical characteristics and lipid profiles of the patients with MS and the control group are shown in Table 1.

The average age of the participants with MS $(40.07 \pm 4.24$ years) was higher than that of the control group ( $31.14 \pm 6.92$ years). Statistically higher BMI, waist circumference, systolic and diastolic blood pressure were found in the

Table 1. Clinical characteristics and lipid profile in patients with metabolic syndrome and in controls

\begin{tabular}{|c|c|c|c|}
\hline Index & $\begin{array}{c}\text { MS } \\
\left(n_{1}=45\right) \\
\end{array}$ & $\begin{array}{c}\text { Controls } \\
\left(\mathrm{n}_{2}=21\right) \\
\end{array}$ & $\begin{array}{c}\text { Significance } \\
(\mathbf{p}<\mathbf{0 . 0 5})\end{array}$ \\
\hline Age (years) & $40.07 \pm 4.24$ & $31.14 \pm 6.92$ & $<0.05$ \\
\hline BMI $\left(\mathrm{kg} / \mathrm{M}^{2}\right)$ & $38.73 \pm 1.84$ & $24.32 \pm 2.71$ & $<0.05$ \\
\hline Waist circumference $(\mathrm{cm})$ & $115.56 \pm 4.78$ & $81.1 \pm 8.4$ & $<0.05$ \\
\hline $\begin{array}{c}\text { Arterial hypertension \% } \\
\text { (number of patients) }\end{array}$ & $77.7(35)$ & $42.9(9)$ & \\
\hline $\begin{array}{l}\text { Systolic blood pressure } \\
\text { (mmHg) }\end{array}$ & $130.68 \pm 15.69$ & $116.67 \pm 15.52$ & $<0.05$ \\
\hline $\begin{array}{c}\text { Diastolic blood pressure } \\
(\mathrm{mmHg})\end{array}$ & $86.33 \pm 7.93$ & $76.19 \pm 9.6$ & $<0.05$ \\
\hline Fasting glucose (mmol/l) & $5.25 \pm 0.24$ & $4.89 \pm 0.47$ & 0.06 \\
\hline Total cholesterol (mmol/l) & $4.51 \pm 0.23$ & $4.47 \pm 0.52$ & $<0.05$ \\
\hline HDL-cholesterol (mmol/l) & $1.03 \pm 0.09$ & $1.26 \pm 0.24$ & $<0.05$ \\
\hline LDL-cholesterol (mmol/l) & $3.42 \pm 0.30$ & $2.58 \pm 0.62$ & $<0.05$ \\
\hline Triglycerides (mmol/l) & $1.59 \pm 0.22$ & $1.06 \pm 0.33$ & $<0.05$ \\
\hline $\begin{array}{c}\text { Triglycerides/total } \\
\text { cholesterol }\end{array}$ & $2.03 \pm 0.87$ & $0.88 \pm 0.27$ & $<0.05$ \\
\hline
\end{tabular}


Table 2. Indices of carbohydrate metabolism (blood glucose, basal insulin levels, HOMA-IR, and HOMA-\%B) in patients with MS and controls

\begin{tabular}{cccc}
\hline Index & $\begin{array}{c}\text { MS } \\
\left(\mathbf{n}_{\mathbf{1}}=\mathbf{4 5}\right)\end{array}$ & $\begin{array}{c}\text { Controls } \\
\left(\mathbf{n}_{\mathbf{2}}=\mathbf{2 1}\right)\end{array}$ & $\begin{array}{c}\text { Significance } \\
(\mathbf{p}<\mathbf{0 . 0 5})\end{array}$ \\
\hline Glucose 0 $\mathbf{m i n}(\mathbf{m m o} / \mathbf{l})$ & $5.25 \pm 0.8$ & $4.9 \pm 0.47$ & $\mathbf{0 . 0 6}$ \\
\hline Glucose 60min $(\mathbf{m m o l} / \mathbf{l})$ & $8.13 \pm 2.25$ & $6.67 \pm 1.56$ & $<\mathbf{0 . 0 5}$ \\
\hline $\begin{array}{c}\text { Glucose 120min } \\
\text { (mmol/l) }\end{array}$ & $6.1 \pm 1.8$ & $5.13 \pm 1.23$ & $<\mathbf{0 . 0 5}$ \\
\hline $\begin{array}{c}\text { Insulin, fasting } \\
\text { (mIU/l) }\end{array}$ & $19.32 \pm 3.22$ & $9.13 \pm 0.74$ & $<\mathbf{0 . 0 5}$ \\
\hline HOMA-IR & $4.62 \pm 0.8$ & $1.97 \pm 0.16$ & $<\mathbf{0 . 0 5}$ \\
\hline HOMA-\%B & $\mathbf{2 5 8 . 7 7 \pm 5 7 . 7 6}$ & $\mathbf{1 8 3 . 3 1} \pm \mathbf{1 0 7 . 9 2}$ & $<\mathbf{0 . 0 5}$ \\
\hline
\end{tabular}

Table 3. The levels of investigated cytokines (IL-1, IL-6 and TNF- $\alpha$ ) in patients with MS and controls

\begin{tabular}{cllc}
\hline Index & $\begin{array}{l}\text { MS } \\
\left(\mathbf{n}_{1}=\mathbf{4 5}\right)\end{array}$ & $\begin{array}{l}\text { Controls } \\
\left(\mathbf{n}_{2}=\mathbf{2 1}\right)\end{array}$ & $\begin{array}{c}\text { Significance } \\
(\mathbf{p}<\mathbf{0 . 0 5})\end{array}$ \\
\hline $\begin{array}{c}\text { IL-1 } \\
(\mathbf{p g} / \mathbf{m l})\end{array}$ & $9.13 \pm 0.74$ & $4.33 \pm 1.46$ & $<\mathbf{0 . 0 5}$ \\
\hline $\begin{array}{c}\mathbf{I L - 6} \\
(\mathbf{p g} / \mathbf{m l})\end{array}$ & $1.97 \pm 0.16$ & $0.51 \pm 0.3$ & $<\mathbf{0 . 0 5}$ \\
\hline $\begin{array}{c}\mathbf{T N F}-\boldsymbol{\alpha} \\
(\mathbf{p g} / \mathbf{m l})\end{array}$ & $\mathbf{2 . 4 9} \pm \mathbf{1 . 1 7}$ & $\mathbf{1 . 1 2} \pm \mathbf{0 . 5 8}$ & $\mathbf{0 . 2 4}$ \\
\hline
\end{tabular}

MS patients. These patients had significantly higher plasma levels of total cholesterol, LDLcholesterol, triglycerides, and lower cholesterol levels compared with the controls. The Tg/HDL ratio in MS group patients was $2.03 \pm 0.87$ vs. $0.88 \pm 0.27$ in the controls $(\mathrm{p}<0.05)$.

The blood glucose levels, endogenous insulin during OGTT, HOMA IR, and HOMA B in the MS group and the controls are shown in Table 2.

There were significant differences in glucose levels at 60 and $120 \mathrm{~min}$ during the OGTT between the two groups. Higher basal insulin levels $(17.08 \pm 9.18 \mathrm{mIU} / 1$ vs. $8.8 \pm 1.64$ $\mathrm{mIU} / \mathrm{l} ; \mathrm{p}<0.05)$, manifested insulin resistance, calculated via HOMA-IR $(3.82 \pm 2.27$ vs. $1.92 \pm 0.41 ; \mathrm{p}<0.05)$ and higher $\beta$-cells function $(245.19 \pm 125.97 \quad$ vs. $128.09 \pm 28.63 ; \quad \mathrm{p}<0.05)$ were detected in the MS patients. The levels of investigated cytokines (IL-1, IL-6andTNF- $\alpha$ ) in the MS patients and the controls are shown in Table 3 .

Patients with MS had significantly higher concentrations of IL-1 $(18.37 \pm 4.28 \mathrm{pg} / \mathrm{ml}$ vs. $7.12 \pm 1.74 \mathrm{pg} / \mathrm{ml} ; \mathrm{p}<0.05)$, IL-6 $(1.01 \pm 0.3 \mathrm{pg} / \mathrm{ml}$ vs. $0.1 \pm 0.3 \mathrm{pg} / \mathrm{ml} ; \mathrm{p}<0.05)$ and TNF- $\alpha(2.13 \pm 1.43$ $\mathrm{pg} / \mathrm{ml}$ vs. $1.82 \pm 0.94 \mathrm{pg} / \mathrm{ml} ; \mathrm{p}=0.24)$. The TNF- $\alpha$ levels did not reveal any statistically significant difference between the study group and the controls. In the MS group, a positive correlation was demonstrated between the level of IL- 1 and the TG/HDL ratio $(\mathrm{r}=0.46 ; \mathrm{p}=0.008), \mathrm{IL}-1$ and HOMA-\%B (r=0.47; $\mathrm{p}=0.005)$.

\section{Discussion}

The studies on plasma triglycerides, total cholesterol, HDL, and LDL cholesterol are established as routine biochemical methods for assessing atherosclerotic risk in patients at increased cardiovascular risk. To improve the screening and identification of at-risk individuals, numerous atherogenic indices have also been created: risk atherogenic indices of Castelli I and Castelli II, the ratio of $\mathrm{Tg} / \mathrm{CDL}-$ cholesterol, and the plasma atherogenic index). In their studies, Da Luz et al. [18] established levels of the Tg/HDL ratio above 2.0 as risk factors and those above 4.0 as the most potent prognostic marker among plasma lipids and atherogenic coronary disease indices. The results of our study showed statistically higher values of the tested atherogenic index $\mathrm{Tg} / \mathrm{HDL}$ cholesterol among MS patients compared to the controls. A positive correlation was also found 
between increased $\mathrm{Tg} / \mathrm{CDL}$-cholesterol ratio and increased mortality and cardiovascular incidents in women [22].

In the MS patients we studied, the TG/HDL ratio was also above 2.0 and corresponded with the increased plasma levels of total cholesterol, LDL cholesterol, and triglycerides. In a study of metabolic-atherogenic parameters among 52 women with MS, Koleva et al. also established statistically higher levels of the $\mathrm{Tg} / \mathrm{HDL}$ cholesterol index $(1.75 \pm 1.11)$ compared to 22 metabolically healthy overweight or obese women $(0.83 \pm 0.36)$ [23]. Our results differed from those from a descriptive study among 500 participants with and without MS in the Pleven region. The researchers found no differences in the TG/HDL cholesterol ratio in the two groups (2.77 vs. 2.6). It should be noted that the average age of the patients with MS surveyed was higher ( $49.3 \pm 6.4$ years) than the age of those we surveyed (40.07 \pm 4.24 years) [24].

In patients with visceral obesity, the presence of dyslipidemia is often combined with IR. On the other hand, the presence of fatty infiltration of the liver and muscles is a factor for IR development. A study among 258 obese without diabetes mellitus found that serum triglycerides, the $\mathrm{Tg}$ / HDL ratio, and insulin concentrations were the best biochemical markers for identifying IR [25]. For the Tg/HDL cholesterol index, a value above 1.8 is considered as an IR indicator. Our results match those of McLaughlin. Depending on ethnicity and gender, different studies show different IR-predictive values of the $\mathrm{Tg} / \mathrm{HDL}$ ratio. For white non-Hispanics and Mexicans, the ratio was over 3.0 [26], and for male AfricanAmericans, it was over 2.5 [27].

In our study, correlational links between the $\mathrm{Tg} / \mathrm{HDL}$ ratio and HOMA-IR were not found. A likely explanation for these results is that the TG/ HDL ratio is an interrupted variable, describing the probability of IR development. The original calculation of IR is achieved by calculating HOMA-IR [28]. It is known that, together with leptin, IL-1modulates lipid metabolism through its ability to suppress the activity of the lipoprotein lipase enzyme [29]. In our MS patients, we found higher serum IL-1 levels and a positive correlation between IL-1 levels and the TG/HDL ratio.

As expected, the levels of IL-6 among the MS patients we studied were also higher than the healthy controls because between $25-30 \%$ of its circulating levels are excreted from fat tissue [30].

As a confirmation of data from a clinical study of Kang among 51 women [31] and in the MS patients we studied, significantly higher concentrations of TNF- $\alpha$ were reported. It is assumed that adipocytes and macrophages located in fat stores serve as a source of TNF- $\alpha$. The concentration of TNF- $\alpha$ increases with obesity and is closely related to IR in peripheral tissues and serum levels of IL-1 and IL-6 [32].

\section{Conclusion}

In conclusion, the results of our study point to a higher TG/HDL cholesterol index among MS patients and correspond to increased levels of HOMA-IR and IL-1 levels in them. Follow-up studies are needed, among a larger group of MS patients, to determine the influence of age and gender on the $\mathrm{Tg} / \mathrm{HDL}$-cholesterol ratio. In addition to the well-established clinical laboratory parameters for identifying patients with MS and IR, the Tg/HDL- cholesterol index is an inexpensive and easy additional indicator, which can be used in routine practice for screening people at increased cardiovascular risk.

\section{References}

1. WHO Consultation. Definition, diagnosis and classification of diabetes mellitus and its complications. Geneva, Switzerland: World Health Organization; 1999:31-3.

2. Executive Summary of The Third Report of The National Cholesterol Education Program (NCEP) Expert Panel on Detection, Evaluation, and Treatment of High Blood Cholesterol in Adults (Adult Treatment Panel III). JAMA 2001;285:2486-97.

3. International Diabetes Federation. The IDF Consensus Worldwide Definition of the Metabolic Syndrome. Brussels, Belgium: International Diabetes Federation; 2006.

4. Bluher M. Adipose tissue dysfunction in obesity. ExpClin Endocrinol Diabetes. 2009; 117:24150.

5. Karastegiou K, Mohamed-Ali V. The autocrine and paracrine roles of adipokines. Molecular and Cellular Endocrinology. 2010;318:1784-92.

6. Leal VO, Mafra D. Adipokines in obesity. Clin 
Chim Acta. 2013;419:87-94.

7. Pereira S, Alvarez-Leite J. Adipokines: biological functions and metabolically healthy obese profile. J Receptor Ligand Channel Res. 2014;7:15-25.

8. Kwiterovich PO. Clinical relevance of the biochemical, metabolic, and genetic factors that influence low-density lipoprotein heterogeneity. Am J Cardiol. 2002;90:30-47.

9. Muniyappa R, Lee S, Chen H, Quon, MJ. Current approaches for assessing insulin sensitivity and resistance in vivo: advantages, limitations, and appropriate usage. Am J Physiol Endocrinol Metab. 2008, 294:15-26.

10. Bonora E, Targher G, Alberiche M, Bonadonna RC, Saggiani F, Zenere MBet al. Homeostasis model assessment closely mirrors the glucose clamp technique in the assessment of insulin sensitivity: studies in subjects with various degrees of glucose tolerance and insulin sensitivity. Diabetes Care. 2000, 23:57-63.

11. Miller WG, Thienpont LM, Van Uytfanghe K, Clark PM, Lindstedt P, Nilsson G et al. Insulin Standardization Work Group: Toward standardization of insulin immunoassays. Clin Chem. 2009, 55:1011-8.

12. McLaughlin T, Reaven G, Abbasi F, Lamendola C, Saad M, Waters D, et al. Is there a simple way to identify insulin-resistant individuals at increased risk of cardiovascular disease? Am J Cardiol. 2005;96:399-404.

13. Liu A, Reaven GM. Is measurement of nonHDL cholesterol an effective way to identify the metabolic syndrome? Nutr Metab Cardiovasc Dis. 2013;23:1122-7.

14. Hadaegh F, Hatami M, Tohidi M, Sarbakhsh P, Saadat N, Azizi F. Lipid ratios and appropriate cut off values for prediction of diabetes: a cohort of Iranian men and women. Lipids Health Dis. 2010;9(1):1-9.

15. Thomas G, Pickering, MD et al. Recomendation for blood pressure measurment in humans and experimental animals, Hypertension, 2004:45:142.

16. Homeostasis model assessment: insulin resistance and beta-cell function from fasting plasma glucose and insulin concentrations in man, Matthews et al. Diabetologia. 1985;28(7):412-9.

17. Matthews DR, Hosker JP, Rudenski AS et al. Homeostasis model assessment: insulin resistance and beta-cells function from fasting plasma glucose and insulin concentration in man. Diabetologia. 1985;28:412-41.

18. Da luz PL, Cesena FH, Favarato D, Cerqueira ES. Comparison of serumlipid values in patients with coronary artery disease at $<50,50$ to 59 ,
60 to 69 , and $>70$ years of age. Am J Cardiol. 2005;96:1640-3.

19. Ke Wan, Jianxun Zhao, Hao Huang et al. The Association between Triglyceride/HighDensity Lipoprotein Cholesterol Ratio and AllCause Mortality in Acute Coronary Syndrome after Coronary Revascularization. 2015 Apr 16;10(4):e0123521.

20. Thomas G, Pickering MD et al. Recomendation for blood pressure measurment in humans and experimental animals. Hypertension. 2004:45:142.

21. Matthews DR, Hosker JP, Rudenski AS et al. Homeostasis model assessment: insulin resistance and beta-cells function from fasting plasma glucose and insulin concentration in man. Diabetologia. 1985;28:412-41.

22. Ke Wan, Jianxun Zhao, Hao Huang et al. The Association between Triglyceride/HighDensity Lipoprotein Cholesterol Ratio and AllCause Mortality in Acute Coronary Syndrome after Coronary Revascularization. 2015 Apr 16;10(4):e0123521.

23. Koleva D, Orbetzova M. Metabolic and Atherogenic Parameters in Women with Metabolic Syndrome and MetabolicallyHealthy Overweight/Obese Women. Endocrinologia. 2017:2:81-6.

24. Naidenova, G. The APO B/APO A1 ratio in determinig the balance between plasma proatherogenic and anti-atherogenic lipoproteins. Medinfo. 2014;1. (In Bulgarian)

25. McLaughlin T, Abbasi F, Cheal K, Chu J, Lamendola C, Reaven G.Use of metabolic markers to identify overweight individuals who are Insulin Resistant. Ann Internal Med. 2003;139(10):802-9.

26. Li C, Ford E, Meng Y, Mokdad A and Reaven G. Does the association of the triglyceride to high-density lipoprotein cholesterol ratio with fasting serum insulin differ by race/ethnicity? Cardiovascdiabetol. 2008; 7:4-10.

27. Sumner AE, Harman JL, Buxbaum SG, Miller BV, Tambay AV, Wyatt SB et al. The triglyceride/ high-density lipoprotein cholesterol ratio fails to predict insulin resistance in African-American women: an analysis of Jackson Heart Study. MetabSyndrRelatDisord, 2010, 8:511-4.

28. Jui- ChiangK, Lai N, Chang J, and Koo M. Predicting insulin resistance using the triglyceride-to-high-density lipoprotein cholesterol ratio in Taiwanese adults. Cardiovasc Diabetol. 2011;10:93.

29. Simi A, Tsakiri N, Wang P, Rothwell NJ. Interleukin-1 and inflammatory neurodegeneration. Biochemical Society Transactions. 2007;35(5):1122-6. 
30. Fried SK, Bunkin DA \& Greenberg AS. Omental and subcutaneous adipose tissues of obese subjects release interleukin-6: depot difference and regulation by glucocorticoid. J. Clin. Endocrinol. Metab. 1998;83:847-50.

31. Kang YE, Kim JM, Joung KH et al. The roles of adipokines, proinflammatory cytokines, and adipose tissue macrophages in obesityAssociated insulin resistance in modest obesity and early metabolic dysfunction. PLoS ONE. 2016;11:e0154003.

32. Winkler G, Kiss S, Keszthelyi L, et al. Expression of tumor necrosis factor (TNF)alphaprotein in the subcutaneous and visceral adipose tissue incorrelation with adipocyte cell volume, serum TNF-alpha, soluble serumTNFreceptor-2 concentrations and C-peptide level. Eur J Endocrinol. 2000;149:129-35.
33. Festa A, D‘Agostino R, Jr, Howard G, Mykkanen L, Tracy RP, Haffner SM. Chronic subclinical inflammation as part of the insulin resistance syndrome: the Insulin Resistance Atherosclerosis Study (IRAS). Circulation. 2000;102:42-7. 